\title{
Young offenders with a learning disability
}

\author{
Ian Hall
}

Young offenders with a learning disability may encounter a variety of different psychiatrists, most of whom do not claim any particular expertise in helping them. Child and adolescent psychiatrists, learning disability psychiatrists and forensic and prison psychiatrists may all see young offenders referred to them who have a learning disability that is, 'mental retardation' as defined in ICD-10 (World Health Organization, 1992) (Box 1). Many of these psychiatrists do not see such referrals as a core part of their role, and perhaps because of this, surprisingly little is known about this group of young offenders. They frequently fall into the borderlands between different types of service provision, and as a result can become marginalised. This is of particular concern since recent work has suggested that young offenders with a learning disability may have substantial mental health needs. This article aims to summarise what is known about this group and describe how some of their mental health needs might be met.

\section{An example from the press}

The following case example, which is taken from a national newspaper, raises some lines of inquiry about young offenders with a learning disability that are subsequently pursued in the article (Box 2).

\footnotetext{
'Wolfboy' guilty of child's murder

A disturbed youth nick-named Wolfboy was yesterday convicted of murdering a nine-year old boy playing in a park on a Sunday afternoon. [The judge] at the Old Bailey ordered that [the youth], aged 17,
}

... be detained at Her Majesty's pleasure. The judge lifted an order he made at the start of the trial banning identification of [the youth].

The victim ... had gone to [a park] a year ago from his home nearby to watch cricket with his father, uncle and brother. He wandered away to play on swings and was seen by several witnesses playing in the park with [the youth]. [The victim]'s naked and battered body was later discovered in dense undergrowth. He had been strangled. [The prosecutor] said the motive was not sexual.

[The youth], nicknamed Wolfboy and Werewolf because of his hairy face and squat build, was well known in [the area] for loitering in public places and approaching strangers, particularly children. After the verdict it was revealed he had a conviction for attacking a boy after taunts about his appearance. [The prosecutor] described [the youth] as "a rather lonely and disordered young man. He is backward, he has a low IQ and he has a degree of mental handicap although not a severe degree."

During the two-week trial [the prosecutor] described the murder as motiveless and said although no one saw it, there was "overwhelming circumstantial evidence" [the youth] was the killer. He was seen with the boy and later in the park crying and with scratches on his face. He told some youngsters: "You'll hear tomorrow there has been a murder in the park." At a nearby supermarket run by friends, he insisted on washing his hands and scouring his shoe. He muttered that the police would not catch him because they would find no evidence.

When he was arrested the next day he told officers "I didn't murder him, he was my best friend." He said he was a horrified witness to the killing carried out by boys who had earlier taunted and then thrown stones at him. [The prosecutor] said [the youth] despite his mental handicaps, displayed "a degree of basic cunning" in the interviews. (The Guardian, 1994, reproduced with permission)

Ian Hall is a consultant psychiatrist for people with a learning disability at Camden and Islington Community Health Services NHS Trust (Islington Learning Disabilities Partnership, 1 Lowther Road, London N7 8SL) and Honorary Senior Lecturer in Psychiatry of Learning Disability at University College, London. He trained at St George's Hospital Medical School, where he developed a research interest in young offenders with a learning disability. 
Box 1. Summary of ICD-10 diagnostic guidelines for mental retardation (WHO, 1992)

A condition of arrested or incomplete development of mind characterised by:

- a significant impairment of overall intelligence, and

- a significant impairment in adaptive behaviour

both of which were manifest in the developmental period

Box 2. Some questions about the case

Do a lot of young people with a learning disability commit offences?

Are they in contact with services prior to the offence?

Is this offence typical?

Is teasing/ridiculing the perpetrator a common factor in the aetiology of offences?

Are children often victims?

Are the crimes committed by young people with a learning disability more easily detected?

Where was the perpetrator detained 'at Her Majesty's pleasure'?

Was treatment offered?

Did the perpetrator learn more constructive ways of dealing with teasing?

\section{Prevalence}

Individuals with mild learning disability show a higher rate of offending compared with peers without learning disability (and peers with more severe learning disability, who rarely commit offences). In a Swedish birth cohort study, Hodgins (1992) found that 'intellectually handicapped' men were three times more likely to offend than men with no disorder or handicap, and five times more likely to commit a violent offence. Women with intellectual handicap were almost four times more likely to offend and 25 times more likely to commit a violent offence than the control group. Most of this offending in those with intellectual handicap was accounted for by excess offending before the individuals were 18 years old.

Most studies have shown a higher than expected rate of learning disability among young offenders in penal institutions. In Britain, this was shown with psychometric testing in borstals (Gibbens, 1963), in approved schools (e.g. Gittins, 1952; Richardson, 1969) and in referrals to youth treatment centres and secure units in community homes with education (Cawson \& Martell, 1979). Approximately $5-13 \%$ of young offenders in these studies had intelligence quotients (IQs) in the range for learning disability (i.e. less than 70). A meta-analysis of the American literature estimated the prevalence of mental retardation among juvenile offenders to be $12.6 \%$ (Casey \& Keilitz, 1990). In contrast, in a more recent British study of the prison service, Gunn et al (1991) found that only $0.2 \%$ of those in youth custody in their survey had a learning disability. This is probably an underestimate, since in this study 'clinical impression' alone was used to detect learning disability, rather than the formal assessment of intellectual functioning used in the other studies quoted, or the additional formal assessment of adaptive behaviour that is ideally required.

\section{Characteristics}

Despite the fact that significant numbers of young offenders have a learning disability, relatively little is known about the particular characteristics of this group compared with their peers without learning disability. Two American studies have looked at the group in some detail: Glueck (1935) studied court referrals and found that, when compared with their more intelligent peers, those with an IQ below 80 had more socio-economic deprivation, and showed more 'liabilities of personality', such as poor emotional control and suggestibility. She found that a greater number of those with lower intelligence had family histories of 'mental defectiveness' and greater rates of illiteracy. They also came from larger families, were in poorer physical health and were more likely to be recidivists. A similar proportion in both the more and less intelligent groups (about 14\%) had other significant mental health problems. Smith et al (1990) showed that while in prison, young offenders with a learning disability were more likely than their peers without learning disability to come into conflict with the prison regime, particularly owing to assaults and 'hygiene violations'.

Sir Cyril Burt (1925) described a typology of 'defective delinquents', with the younger ones being easily led and the older ones 'leading astray' much younger peers. He claimed that 'defective delinquents' are less likely to commit fraud, forgery or embezzlement, but more likely to commit vagrancy, sexual offences and robbery with violence than are other young delinquents. However, this typology should be viewed 
with caution since Burt does not present the data from which these conclusions are drawn, and his subsequent work in related fields has been seriously questioned. In a study in British borstals, Gibbens (1963) found that among these young offenders, 'intellectual dullness' was associated with 'proving' offences, delayed onset of sexual activity, late onset of criminal behaviour and membership of social class V. Cawson \& Martell (1979) comment that among the referrals to youth treatment centres and secure units in community homes with education that they studied, those with a learning disability often showed 'trivial' delinquency, but "aggressive and irresponsible behaviour towards younger children".

Young people with a learning disability in general are known to have high rates of psychiatric disorder compared with their peers without learning disability. Prevalence rates of between $41 \%$ and $50 \%$ have been found in several studies, with antisocial and disruptive behaviour being particularly common among those with mild learning disability (Tonge, 1999). However, the relationship between psychiatric morbidity and offending behaviour has not been well explored in this group.

\section{New research}

In a recent study (Hall, 1999), I attempted to provide a better description of the clinical characteristics of young people with a learning disability in Health and Social Service-run secure units. I found that those with a learning disability:

- usually had a learning disability in the mild range;

- showed a particular pattern of impairment of social and communication skills relative to their other skills and their intellectual level;

- had a very high prevalence of psychiatric disorder, including disruptive behavioural disorders (e.g. conduct disorder), mood disorders, anxiety disorders and substance use disorders; this was in common with their peers without a learning disability, although those with a learning disability were less likely to be suicidal; and

- had had a greater number of placements outside the family home, and had spent much more of their lives away from their family than their peers without learning disability.

The concept of 'diagnostic overshadowing' is therefore highly relevant. It is important not to assume that because a young offender has a learning disability that all his or her problems are attributable
Box 3. Summary of prevalence and characteristics of young offenders with a learning disability

People with mild learning disability are more likely to commit offences than those without learning disability

They are likely to come from deprived and disrupted backgrounds

They may have particular difficulty coping with prison

They may have relative impairments of communication and social skills

They may have specific psychiatric disorders that are masked by the learning disability

to the disability per se. He or she may well have other diagnosable psychiatric disorders as well as particular impairments in adaptive behaviour skills. Recognition of these additional problems may suggest specific interventions that improve an individual's functioning and reduce offending behaviour.

\section{Assessment}

Psychiatrists may be asked to assess young offenders with a learning disability in a variety of community settings, and also in institutional settings such as prisons, residential schools and court diversion schemes. The assessment may be for a number of different purposes - for example, to advise on diagnosis, treatment, management of behaviour, placement, dangerousness or prognosis.

\section{Information gathering}

Young offenders with a learning disability have often led complicated lives, and effort expended in gathering information about the systems they have been involved with usually pays dividends. Interviewing informants and perusing written information are essential techniques for getting historical as well as present state data.

Young offenders with a learning disability very often have adverse family backgrounds. West \& Farrington $(1973,1977)$ found that coming from large families, poverty, unsatisfactory parental childrearing behaviour and parental criminality were all predictive of juvenile delinquency. Similarly, Rutter \& Madge (1976) found that poverty, family 
disorganisation, overcrowding and large families were all associated with mild mental retardation. It is therefore useful to enquire exactly what the family circumstances are and be alert to potential adverse events such as bullying and abuse. Children with a learning disability are in general more sensitive to such adverse events because they are in a more dependent position in relation to their carers than children without learning disability, and have fewer internal resources to deal with such trauma.

Adolescents with a learning disability who offend will usually have been regarded as having 'special educational needs'. Psychometry is somewhat out of vogue with educational psychologists and teachers, and so their reports in statements of special educational needs can be vague regarding individuals' particular skills and deficits. It may also mean that a mild learning disability may be missed, particularly when there is a comorbid behavioural disturbance. In recent years, special educational provision has been made increasingly within mainstream schooling, although young offenders with a learning disability may have attended all types of special school, including those for 'moderate learning difficulties', 'severe learning difficulties', 'emotional and behavioural disturbance' or for 'delicate' children with physical disorders.

In our recent study of adolescents in secure units, we found that those with a learning disability had had, on average, more placements outside the family home than their peers without disability. Young offenders with a learning disability are therefore highly likely to have had previous contact with services, and may well have moved placement frequently. It can be difficult to disentangle cause and effect in individuals with such a history, but where care placements are changing every few months this is likely to have a profound effect on an individual's feelings of attachment and their emotional development.

Certainly, the recent White Paper Modernising Social Services (Secretary of State for Health, 1998) acknowledges that children have not been sufficiently protected from abuse in residential settings and foster care. It also states that too many young people are placed too far away from home, with such placements often not being properly monitored by local authorities.

\section{Interview}

Ideally, the interview with the client should be conducted over more than one session. This is because it may take longer to build a rapport with someone with a learning disability (particularly if they are in alien or uncomfortable surroundings), and less information is likely to be gathered at each session. For example, it may take a long time to elicit mental state findings. In addition, a greater amount of information may be required, particularly about intellectual skills and adaptive behaviour. For these reasons, it is important to insist on an appropriate setting for an interview, so that it can be conducted in a relaxed and private manner. Where there are obvious communication problems, it can be helpful to seek the advice of a speech and language therapist prior to a second interview.

It is particularly important to seek out informants and collect historical and present state information from them, as they may have a much better idea than a visiting psychiatrist will about an individual's dayto-day functioning in their usual environment. However, informants may be unaware that someone has a mild learning disability, particularly if there are comorbid mental health problems. Gudjonsson et al (1993) have demonstrated the difficulties in identifying such vulnerabilities in adults in police custody.

Mental illness in young offenders with a learning disability can present in a very non-specific way, frequently with behavioural disturbance or social withdrawal, so it is especially important to enquire directly about psychiatric symptoms in very clear and straightforward language. I have found the Child Assessment Schedule (Hodges, 1993) to be a useful structured diagnostic interview that young offenders with a learning disability find easy to understand. People with a learning disability in general have higher rates of mental illness thanpeers without disability, and there are certain conditions such as autism to which they are much more prone, so it is certainly worthwhile undertaking a systematic and detailed enquiry.

Learning disability is diagnosed on the basis of there being significant impairment of both intellectual functioning and adaptive behaviour (or social functioning) arising in the developmental period. Young offenders with a learning disability are likely to have 'failed' in various settings beforehand, so assessment needs to be sensitive to this. However, when making recommendations about treatment and placement, it is very useful to have a detailed picture of both intellectual functioning and adaptive behaviour skills. This is because specific relative deficits are likely to be found that may suggest particular intervention strategies. For example, there may be particular deficits in communication skills that can be addressed through education or speech and language therapy, or there may be specific problems with social skills that lead to misunderstandings and behavioural disturbance.

Research on the offending profile of young offenders with a learning disability is thin on the ground and different studies are somewhat conflicting. However, it is certainly true that young people with a learning disability may be led into crime by their 
more able peers, or even those younger than themselves. This was the case with the recently pardoned Derek Bentley, who was hanged after his younger accomplice shot and killed a policeman in a bungled break-in. Particular psychiatric disorders, especially those on the autistic spectrum, may be highly relevant to the motivation behind criminal behaviour, for example, with the development of highly idiosyncratic sexual fetishes. Psychiatrists may associate arson and sexual offences with people with a learning disability. This is somewhat erroneous; arson and sexual offences have been found to be relatively more common only among adults on hospital orders (Walker \& McCabe, 1973; Kearns \& O'Connor, 1988). As with other groups of offenders, property offences (excluding arson) are by far the most common (Day, 1990).

Young men with a learning disability may be particularly suggestible during interviews in connection with offences, which can potentially lead to miscarriages of justice. Where this is an issue, suggestibility can be assessed using the Gudjonnson Suggestibility Scale (Singh \& Gudjonsson, 1992), which provides a relatively objective measure with which the courts have some familiarity.

\section{Management}

\section{Prevention and early intervention}

Many children with mild learning disability who go on to commit offences will have been known to Education or Social Services departments from an early age, and some will be known to child psychiatry services. Research evidence for the value or otherwise of early intervention programmes in this group is limited. However, as more and more children with mild learning disability attend mainstream school, it is especially important that the additional support they require is not sidelined because of the wider agenda of the school. Similarly, in schools for children with 'emotional or behavioural disturbance', children with mild learning disability may not have all their learning needs recognised because of more obvious behavioural problems. It would also seem relevant to try to improve the social care of children with a learning disability, since those who go on to offend have often experienced a large number of social care placements and considerable social adversity.

\section{Management of offenders}

As with other offender groups, it is necessary in the management of young offenders with a learning disability to balance the needs of the individual

\section{Box 4. Clinical interview checklist}

More than one interview is usually required

See the young offender in as relaxed and natural a setting as possible

Direct observation of mental state and informant reports are essential

Use straightforward language and check understanding

Remember that learning disability can mask mental illness

Consider the use of standardised assessment tools

Consider the role of the learning disability/ skill deficits and mental state in the offending behaviour

against the needs and demands of society. Where offences are minor or victimless, individual needs are more important. Court appearances and assessments in relation to these may lead to accessing appropriate community services, although offenders in late adolescence may fall foul of boundary disputes between child and adult services.

For those whose offence is more serious, the needs of society may dictate that custodial care is required for a time. For young people with a learning disability in the UK, this can mean a variety of institutions in the health care, social care, education and penal sectors (Box 5) (after Sheldrick, 1990).

There is very little specific provision for young offenders with a learning disability, with the exception of a secure adolescent unit for learning disability in the private/independent health care sector and a non-secure National Health Service adolescent unit for learning disability in the north of England. All the units listed in Box 5 may take young offenders with a learning disability, but their philosophies can differ. Health care, social care, education and containment are all elements that are required in the management of young offenders with a learning disability, but which may be lacking in some of these places. For example, specialist educational facilities are unlikely to be available in prisons, and the provision of specialist health care (including psychiatry, psychology, occupational therapy and speech and language therapy) can be very limited in special boarding schools, children's homes and prisons. It is likely that young offenders with a learning disability are especially vulnerable in penal institutions. Certainly in the USA they were found to make a much poorer adjustment to prison regimes, and so get into much more trouble (Smith et al, 1990). 
New research

Notwithstanding this variability in approach, it can be difficult to decide what criteria are used to determine the most appropriate provision for an individual. In our study (Hall, 1999), we compared a secure unit in a community home with education with a secure adolescent unit in the private health care sector. We found young people with a learning disability with a remarkably similar range of psychiatric diagnoses, a similar degree of behavioural disturbance and similar patterns of skills and impairments in both units. It did not therefore seem that people were being selected for these units on these criteria. We did, however, find that indices of suicidal behaviour were more common in those in health care provision, and this may represent an important reason for using this resource. We also found that a greater history of offending was present in those in the social care institution, so this may be a more favoured option by the courts.

\section{Clinical pathways}

The pathways to care that young offenders with a learning disability take can seem haphazard. Offending behaviour may or may not be dealt with by the criminal justice system, depending partly on the seriousness of the offence, but also on many other factors. These include the attitudes of individual police officers and others already involved, such as family, care staff, social workers, schools and psychiatrists. Whether other agencies are already involved can significantly influence the path that the young person takes.

Box 5. Examples of facilities that may look after young offenders with a learning disability

Young offender institutions (HM Prison Service)

Community homes with education (Social Service departments)

Children's homes with or without secure units (Social Service departments and independent sector)

Special boarding schools (education departments)

Youth treatment centres (Department of Health)

NHS adolescent units

Private hospital adolescent units
Many of those whose behaviour problems are less serious do not become subject to legal controls, although they are likely to be in contact with some services, for example, special education, Social Services, child and adolescent mental health services. The legal instruments that may be used on young people (up to the age of 18) in addition to sentencing within the prison service are outlined below.

\section{Mental Health Act}

Most young offenders with a learning disability who commit serious offences meet the criteria for 'mental impairment' under the 1983 Mental Health Act, and are of an age where it would be difficult to say that 'treatment' would be ineffective. Most of those in secure psychiatric hospitals are detained under the Act. However, there are many more young offenders with a learning disability who have their freedom restricted who are not in hospitals and not subject to the Act, even though they may meet criteria for its use. Given the variability of health care provision in other settings, perhaps more consideration should be given to diverting young offenders out of the criminal justice system by suggesting use of the Act. Both civil sections under Part II and criminal sections under Part III of the Act are appropriate, although section 36 (remand to hospital for treatment) does not apply to those with 'mental impairment' under the Act. For all those sentenced to youth custody by the courts, therapeutic options in such penal institutions are limited, but those meeting the criteria for 'mental impairment' (or another mental disorder under the 1983 Mental Health Act) can be transferred to hospital using section 47.

\section{Other methods}

Secure accommodation orders under the Children Act 1989 may be used to detain young offenders in social care institutions, the Youth Treatment Service and psychiatric hospitals. These include private and voluntary as well as statutory agencies. Those convicted of the most serious offences have orders made by the courts under section 53 of the Children and Young Persons Act 1933, and this can be used to detain people in youth custody, Social Services care or in the Youth Treatment Service.

\section{Personal view}

The previous government advocated a policy of 'understand less and punish more' with regard to young offenders. Penal institutions are of course much 
cheaper to run than most of the other facilities listed in Box 5, although it would be cynical to suggest that this was the sole motivation behind the policy. The particular vulnerability of young offenders with a learning disability in prison, demonstrated by Smith et al (1990), might suggest that these other facilities may be better able to meet their needs, despite few being particularly for people with a learning disability. Although these units deal with fairly similar client groups, there are marked differences in ethos in the different units. The paradigms used to understand young people's behaviour and the difficulties they face are also different, and a medical or biopsychosocial understanding may not be available. This inevitably means that the type of 'treatment' available is very variable, particularly in social care and penal institutions. In our study, we came across several examples of young offenders with a learning disability with previously undiagnosed and therefore untreated mental illnesses. Similarly, depending on the institution, communication needs may go unaddressed, as may educational needs, particularly in those aged 16 or over. If these mental health and other needs go unacknowledged and unaddressed, then this is likely to have adverse consequences both for the individual and for society.

\section{Summary}

A significant minority of young offenders have a learning disability. They are particularly vulnerable, but may be difficult to identify because of comorbid mental health problems or behavioural disturbance. They have often been well known to children's services, especially social care. There are few services specifically designed to help this group of offenders, and they are likely to become marginalised. Recent work has suggested that the detailed assessment of individuals may lead to more holistic treatment, including the treatment of specific mental disorders. This may in turn improve prognosis for the individual, and reduce the risks to society.

\section{References}

Burt, C. (1925) The Young Delinquent, London: University of London Press.

Casey, P. \& Keilitz, I. (1990) Estimating the prevalence of learning disabled and mentally retarded juvenile offenders. In Understanding Troubled and Troubling Youth (ed. P. E. Leone). Newbury Park, CA: Sage Publications.

Cawson, P. \& Martell, M. (1979) Children Referred to Closed Units. London: HMSO.

Day, K. (1990) Mental retardation: clinical aspects and management. In Principles and Practice of Forensic Psychiatry (eds R. Bluglass \& P. Bowden). Edinburgh: Churchill Livingstone.
Gibbens, T. C. N. (1963) Psychiatric Studies of Borstal Lads. Oxford: Oxford University Press.

Gittins, J. (1952) Approved School Boys. London: HMSO

Glueck, E. T. (1935) Mental retardation and juvenile delinquency. Mental Hygiene, 19, 549-572.

Gudjonsson, G., Clare, I., Rutter, S., et al (1993) Persons at Risk During Interviews in Police Custody: The Identification of Vulnerabilities. London: Royal Commission on Criminal Justice, HMSO.

Gunn, J., Maden, T. \& Swinton, M. (1991) Mentally Disordered Prisoners. London: Institute of Psychiatry.

Hall, I. S. (1999) Young People with a Learning Disability in Secure Health and Social Services Care: A Descriptive Study. MPhil thesis. St George's Hospital Medical School, University of London.

Hodgins, S. (1992) Mental disorder, intellectual deficiency, and crime: evidence from a birth cohort. Archives of General Psychiatry, 49, 476-483.

Kearns, A. \& O'Connor, A. (1988) The mentally handicapped offender: a 10-year study of two hospitals. British Journal of Psychiatry, 152, 848-851.

Richardson, H. J. (1969) Adolescent Girls in Approved Schools. London: Routledge \& Kegan Paul.

Rutter, M. \& Madge, N. (1976) Cycles of Disadvantage - A Review of Research. London: Heinemann Educational Books.

Secretary of State for Health (1998) Modernising Social Services - Promoting Independence, Improving Protection, Raising Standards. London: The Stationery Office.

Sheldrick, C. (1990) Treatment and Facilities: Child Custody. In Principles and Practice of Forensic Psychiatry (eds R. Bluglass \& P. Bowden). Edinburgh: Churchill Livingstone.

Singh, K. K. \& Gudjonsson, G. H. (1992) Interrogative suggestibility among adolescent boys and its relationship with intelligence, memory, and cognitive set. Journal of Adolescence, 15, 155-161.

Smith, C., Algozzine, B., Schmid, R., et al (1990) Prison adjustment of youthful inmates with mental retardation. Mental Retardation, 28, 177-181.

Tonge, B. J. (1999) Psychopathology of children with developmental disabilities. In Psychiatric and Behavioural Disorders in Developmental Disabilities and Mental Retardation (ed. N. Bouras). Cambridge: Cambridge University Press.

Walker, N. \& McCabe, S. (1973) Crime and Insanity in England. Vol 2: New Solutions and New Problems. Edinburgh: Edinburgh University Press

West, D. J. \& Farrington, D. P. (1973) Who Becomes Delinquent? London: Heinemann Educational.

_ \& \& - (1977) The Delinquent Way of Life. London: Heinemann Educational

World Health Organization (1992) The ICD-10 Classification of Mental and Behavioural Disorders: Clinical Descriptions and Diagnostic Guidelines. Geneva: WHO.

\section{Multiple choice questions}

1. With reference to people with a learning disability: a in the UK, the diagnostic criteria for learning disability are substantially different from 'mental retardation' in ICD-10

b most people with a mild learning disability meet the criteria for 'mental impairment' under the Mental Health Act 1983 in England and Wales.

c those with a mild disability are more likely to commit offences than the general population

d sexual offences are one of the most common types of offence committed by people with learning disability

e 'diagnostic overshadowing' refers to other diagnoses masking the learning disability. 
2 In adolescence:

a people with a mental illness can be detained against their will only in penal institutions, hospitals and nursing homes

b coming from a large family and living in poverty are both associated with juvenile delinquency

c coming from a large family and living in poverty are both associated with mild learning disability

d those with significant conduct disorder are unlikely to have a learning disability

e educational psychologists have moved towards more objective testing over the past 10 years.

3 Young offenders with a learning disability:

a have significantly more problems adjusting to prison life compared with other young offenders

b have relatively good communication skills compared with their other skills

c in social care placements are not likely to have major mental health problems

d are unlikely to have been cared for outside the family home

e may have behavioural problems owing to mental illness attributed to their learning disability.

$\begin{array}{llll}\text { MCQ answers } & & & \\ & & & \\ \text { 1 } & \text { 2 } & & 3 \\ \text { a F } & \text { a F } & \text { a T } \\ \text { b F } & \text { b T } & \text { b F F } \\ \text { c T } & \text { c T } & \text { c F F } \\ \text { d F } & \text { d F } & \text { d F } \\ \text { e F } & \text { e F } & \text { e T }\end{array}$

\section{MCQ answers}

\section{Commentary}

\section{Jane McCarthy}

I am certain this review by Hall is welcomed by psychiatrists working across a number of specialities, who in the course of their work are asked to assess a young offender with a learning disability. The main difficulty the paper highlights is how little research has been undertaken in this area, leaving clinicians to rely on their experience and that of a handful of colleagues specialising in this area. The literature on the more able population is a useful source of information, as there is considerable overlap between the two groups.

\section{Preventive approaches}

There are three types of preventive activity. Primary prevention involves stopping the offending behaviour occurring. Secondary prevention entails providing treatment to a young offender in order to prevent a recurrence. Tertiary prevention focuses on the group who continue to present a high risk of offending despite interventions and so requires attention to their appropriate care, with the careful planning of specialist services.

To undertake preventive approaches with this group we need to understand the factors that lead to offending behaviour. Hall outlines the characteristics of young offenders with a learning disability. These factors include socio-economic deprivation, temperament problems, originating from large families, impaired social and communication skills, presence of psychiatric disorder and having experienced a number of placements outside the family home. Primary prevention needs to focus on children with low abilities from impoverished backgrounds.

Jane McCarthy is a consultant psychiatrist for childen and adolescents with a learning disability at Northgate and Prudhoe National Health Service Trust (Prudhoe Hospital, Prudhoe, Northumberland NE42 5NT) and Senior Lecturer in Psychiatry of Learning Disability at the University of Newcastle. Her research interests are psychopathology and specialist health services for young people with a learning disability. 